\title{
The innovation and exploration of the original animation talent training mode of the mathematics and media major in colleges and universities
}

\author{
Kang Kai \\ Xi'an University, Shaanxi, China, 710065
}

Keywords: Media Major; Original; animation talents; training mode; innovation

\begin{abstract}
The Chinese animation market has a good prospect, but it is still the main profit-making project. This is very disadvantageous for the animation industry which will be on the road of sustainable development. The industrial structure must be transformed from the processing to the original in order to solve the fundamental problems of development. The change of the industry demand has led to the change of the mode of cultivating talents in animation education. It is necessary to cultivate the animation talents with high quality and originality. This paper also probes into the innovation of the creative talent training mode of the mathematics and media major in colleges and universities.
\end{abstract}

\section{The analysis of animation industry and the animation education background}

1) The current world animation market promises enormous potential According to the survey, Disney alone is able to make $\$ 500$ billion a year, and the Japanese animation industry overtook its total production of cars in 2003. Although China's animation market has huge development space, but the market share is very limited. Japanese animation accounts for 60 per cent of the market, while European and US animation accounts for 29 percent, the local original animation (including Hong Kong and Taiwan) has less than 11 per cent of the market. Therefore, it is not enough for China's animation industry to revitalize its industry by contract and imitation, and the industrial structure must be transformed from the processing to the original. This is bound to bring about the change of the type of talent demand, from the past one-sided technical demand, gradually transformed into the creative, cultural, artistic demand

In the animation specialty education, the specific cultivation way will also gradually follow up the transformation, the industry demand will make the "small but fine" but the outstanding characteristic pattern replace the past "big but full" but the whole level low the training mode, in the transformation of the cultivation mode, the most crucial is to the original animation talent more intense demand.

2) Due to the long-term incompleteness of the animation industry chain in our country, the late marketing rights and interests are not clear, which leads to the low profit of the producer and therefore does not attract high-quality talents. So at this moment, the culture of the domestic animation practitioners is generally low. It has the congenital deficiency to promote the cultural value of animation products, the creation of a local cartoon brand image which hinders the whole 
cartoon industry virtuous circle, becomes the weak link in the process of Chinese animation industry chain. It also makes the correct cultivation of cartoon talents in colleges and universities appear to be more urgent.

The survey shows that $90 \%$ of the college animation major in the country has the problem of insufficient teachers, disordered curriculum, and teaching from reality. The resulting students are not strong in the field, have no ability to innovate and can not meet the needs of industry and enterprises. Some experts pointed out that: "The development of Animation Education and animation industry development of the actual demand disconnect, the professional setting is concentrated in the production link, while the animation planning, creative, screenwriting, management, Marketing promotion, copyright agency, derivative product development and so on, lack of conformity with changing market requirements; low level of literacy among short-term vocational trainers has resulted in a congenital deficiency at the beginning of the animation industry chain. All these have seriously affected the healthy development of the whole industry, which makes it urgent for colleges and universities to improve the thought, method, and mode of animation talent training.

\section{Analysis of the present situation of Animation Education}

1) In view of the problems facing the animation education in colleges and universities at present, many experts point out that the main problem is that the university does not know enough about the nature of animation industry and only pays attention to the medium-term production technology, to equate college education With vocational training courses. Many College animation majors do not rely on their own academic characteristics, advantages, and in combination with professional characteristics to determine the goal of talent training, overemphasis on processing technology, the training of animation talent "quality is not high, professional is not fine "It has been made clear by some scholars that: The essence of animation industry is the "culture" industry, its core competence is valuable cultural symbol innovation, and the animation is involved in a large number of disciplines, the cultural resources of demand are enormous, as a scientific and cultural institution, colleges and universities have the ability and obligation to adjust their resources to provide the conditions for the training of cartoon talents to support the development of the National Animation Industry.

2) With the increasing clarity of industry demand and the correct understanding of the nature of the animation industry, many universities are currently exploring innovations in the curriculum of animation teaching It changed the tendency of remaking and processing technology and light culture original ability and cultivation. In the course setting of animation teaching, we gradually integrate the characteristics of culture history, film history, art history, art appreciation, Chinese pen and ink painting, and so on They compress unnecessary courses, strengthen features and cutting-edge learning, and provide the market with truly qualified people.

3) Current status of vocational training. The examination of short-term animation vocational training courses found that most of their sources were not college-educated, and that their training was more focused on skills learning and training, with a focus on imitation of mainstream design, lack of creative training. This indicates that short-term vocational training is difficult to produce original talents, while the improvement of animation education in colleges and universities urgently needs the mode of combining study and study.

\section{The innovation of the training mode}

Through studying the general development course and trend of the animation industry and the field investigation to the industry, and analyze the operation of the animation teaching resources in 
all relevant colleges and universities, to fully understand the advantages and disadvantages of the training of cartoon talents in colleges and universities, this paper puts forward the teaching problem and innovative scheme that the mathematics and media major of university should cultivate the original cartoon man:

The teaching problem to be solved by cultivating the original cartoon man:

1) To improve the animation education in colleges and universities, to meet the demand of the animation industry to the original talents.

2) Avoid the cultivation mode of animation talents in colleges and universities to a certain extent from the actual demand of the industry.

3) To strengthen the use of teaching resources in colleges and universities in the process of cultivating original animation talents.

Most of the arts majors adopted the traditional soviet-style art cultivation mode in the early stage of cultivation, namely, from the basic modelling, light and shadow. Although four years of undergraduate education, the actual time available for professional study is very limited. If there is no basic teaching and training for the demand of the animation major at the beginning of the training, it is very disadvantageous to the follow-up course of animation specialty. Therefore, it is necessary to enlarge the specific demand of the animation profession in the basic shape and the ability of the color expression in the initial stage of cultivation, rather than a comprehensive but obvious teaching model. If the speed-writing course should increase the proportion of dynamic sketch, the content of the basic structure, force and momentum of human body and animal should be increased in the sketch course. The color course should emphasize the content of the theory of mode, color emotion and color, instead of the traditional long-term work, the pursuit of light and shadow and texture, the pursuit of painting skills for the purpose. To cultivate students' aesthetic interest from the beginning of teaching.

From the experience of most art students, the whole process of middle school education is filled with the average learning of all kinds of cultural classes, and the cultivation of aesthetic ability and aesthetic interest is very little. In the future, it is impossible to meet the needs of complex industries, but to train high-level talented people with original ability, to improve the aesthetic interest will become the focus of the cultivation model. Therefore, at the beginning of teaching, we must improve the students' aesthetic vision through various kinds of targeted appreciation and humanistic courses, so as to make the students' Eyes Taller. Building a network node for the course

In the undergraduate education system, the link between curriculum and curriculum will directly reflect the integrity of the training model, the system, the science. Therefore, based on the advantages of teaching, the development of teachers' potential, the establishment of the modular curriculum-based spiral-type teaching model, from its own advantages of teaching resources to choose the animation industry-related nodes as the basis, construct the network node of the course, effectively organize the course connection and the teacher teaching the professional skill connection.

4) Strengthen school-enterprise cooperation and implement project-based teaching.

In order to strengthen the goal of talent training, the teaching and employment seamless joint, it is necessary to do good cooperation between school and Enterprise. The school-enterprise co-operation is beneficial to the cultivation of applied talents in this major, the company and the school cooperation, can bring to the students deep original first-line job opportunity, master the design and production technology of the industry, be familiar with the design and production process of the enterprise, take the project to drive the student to carry on the specialized study, avoid the student after graduation meets with the society, with the industry disjuncture predicament.

Through the project teaching, the enterprise uses the school's professional resources to carry on the project to carry on the project, invests a large number of the first-line experience main person, 
cooperates with the media professional teacher, brings the student to participate in the project design and the production, can effectively mobilize the participation of the existing teachers, so that the professional teachers in colleges and universities will further work on the front-line work and gradually adapt to the standards of work in the industry and further enhance their business standards, lay a good foundation for becoming a "dual-teacher" teacher. At the same time, the advantages of being in the university can be developed in the practical scope of innovative research, help with the long-term development of the profession.

5) the road of the integration of study and research in the way of the implementation of the studio system.

Through the cooperation between school and enterprise and the project teaching, it can greatly improve the professional skills of teachers and students, and gradually have the ability to plan and make the practical business project gradually, strengthen the mode of the integration of the production and study, make the teaching way gradually to get rid of the traditional classroom teaching, but also can strengthen the students' technology can bring great original space for students at the same time, but also make teachers' professional quality and research ability further improve

6) Strengthen the development of an open experimental platform.

With the implementation of the integration of school-enterprise cooperation and production and research, it is imperative to build an open experimental platform. The construction of open experimental platform is beneficial to the project-based teaching of teachers and students, and is conducive to the development of independent innovation projects of students, and is conducive to the implementation of the enterprise. Of course, the management of the laboratory must be aligned with the planning and construction of the complete system

7) Strengthen the "two-teacher" construction.

To strengthen the construction of the dual-teacher type is one of the necessary conditions to strengthen the training of original animation talents. As the main role of cultivating talents, teachers lack industry knowledge, do not know the industry norms and standards, without the involvement of commercial projects, it is bound to become a stumbling block to the success of teaching. Therefore, professional teachers should be strongly supported to stand-up internships, take part in business training, participate in business projects, and improve teachers' professional skills in order to improve their teaching standards

\section{Conclusion}

Through the promotion of the reformed training model can improve the animation education in colleges and universities, and meet the demand of the animation industry for original talents, and make the animation talent training mode of colleges and universities more close to the actual demand of the industry, so as to fully explore the resources of animation education in colleges and universities, and to alleviate the surface shortage of animation teachers in universities. At the same time, in the cultivation of original animation talents, can enhance the utilization of their own teaching resources in institutions of higher learning and give full play to the advantages of long education cycle, rich cultural resources and high innovation, for the local animation industry to transport more outstanding original talent.

\section{References}

[1] Li Sida.Overview of Digital Media Art [M] 2015.

[2] Li Sida.A brief history of Digital Media Art [M] 2017.

[3] Yang Xiaolin. Introduction to Hollywood animated movies [M] 2012.

[4] Feng Wen.Animation overview [M] 2011.

[5] Zhang Jian A sword.Research on the cultivation of digital media arts talents in local universities [J].Art And 
design, Changsha University of Science and Technology School of design arts,2013.(10)175-176

[6] Yang Xiangmin, Wang Ping. A probe into the construction of digital media arts and the mode of teaching cultivation [J]. Creative and design, Nanjing University of Posts and Telecommunications Media \& Arts Institute, 2016. (01) : 79-84

[7] Ye Zhenyan. Research on the present situation analysis and teaching system of Digital Media Arts in colleges and universities [J].Journal of Jishou University (Social Science) Zhuhai College, Jilin University, 2017.(s 1)151-153

[8] Liu Jurmin. Discussion on the training of Digital Media Arts Professionals [J]. Public Art, Nanjing Visual Arts Vocational College Media Department, 2012. (20) 265-266 